\title{
Comparison of Bacterial Load Parameters in Subgingival Plaque during Peri-implantitis and Periodontitis Using the RT-PCR Method
}

\section{Usporedba parametara bakterijskog opterećenja u subgingivalnom plaku kod parodontitisa i periimplantitisa metodom RT-PCR}

\author{
${ }^{1}$ Medical Faculty, Pavol Jozef Šafárik University, Košice, Slovak Republic \\ Medicinski fakultet Sveučilišta Pavol Jozef Šafárik, Košice, Republika Slovačka \\ 2 Faculty of Dentistry, Uzhhorod National University, Uzhhorod, Ukraine, \\ Stomatološki fakultet Nacionalnog sveučilišta Uzhhorod, Uzhhorod, Ukrajina \\ 3 Faculty of Dentistry, State University of Campina Grande-Paraiba, Campina Grande, Brazil \\ Stomatološki fakultet Državnoga sveučilišta Campina Grande-Paraiba, Campina Grande, Brazil \\ ${ }^{4}$ Faculty of Dentistry, Dicle University, Diyarbakir, Turkey \\ Stomatološki fakultet Sveučilišta Dicle, Diyarbakir, Turska \\ 5 Medical Faculty, Bogomolets National Medical University, Kyiv, Ukraine \\ Medicinski fakultet Nacionalnog medicinskog Sveučilišta Bogomolets, Kijev, Ukrajina
}

\section{Abstract}

Objective: To estimate the actual parameters of bacterial load in subgingival plaque during periodontitis and peri-implantitis pathologies using the RT-PCR (real-time polymerase chain reaction) method and evaluate their associations with clinical periodontal indicators. Materials and Methods: Five different groups of subjects were selected according to a formulated design of the study: with mild/ moderate periodontitis, with severe periodontitis, with peri-implantitis, healthy periodontal group and healthy peri-implant group. Subgingival plaque samples were formed with paper points inserted in the pocket/sulcus area for 30 seconds. A standardized test the "ParodontoScreen" was provided for identification of target opportunistic pathogens (A. actinomycetemcomitans, $P$. gingivalis, $T$. forsythia, $P$. intermedia, T. denticola) by the RT-PCR. Results: Bacterial load parameters demonstrated a significant tendency towards an increase within periodontitis progression and during the presence of peri-implantitis pathology. Each targeted mean bacterial load level was statistically associated with periodontitis or peri-implantitis pathology $(p<0,05)$ according to the provided univariate analyses and upon condition that bacterial load parameters of healthy sites were used as reference for equiparation. The highest correlation values were found between periodontal probing depth and bacterial load parameters of $A$. actinomycetemcomitans $(r=0,37 ; p<0,05)$ and $P$. gingivalis $(r=0,28 ; p<$ $0,05)$; and also between clinical attachment loss and bacterial load values of $A$. actinomycetemcomitans $(r=0,38 ; p<0,05)$ and $P$. gingivalis $(r=0,24 ; p<0,05)$. Conclusions: Periodontitis and peri-implantitis are associated with the same microbial pathogens even though the distribution pattern of their bacterial load and detection frequency parameters registered with RT-PCR could be distinct and linked to the individual patient-related conditions and the severity stage of pathology.
Received: November 15, 2019

Accepted: January 24, 2020

Address for correspondence Myroslav Goncharuk-Khomyn Uzhhorod National University Faculty of Dentistry Uzhhorod, Ukraine myroslav.goncharuk-khomyn@ uzhnu.edu.ua

Key words

Periodontitis; Peri-implantitis; Bacterial Load; Real-Time Polymerase Chain Reaction

\section{Introduction}

Although periodontitis and peri-implantitis pathologies have been associated with impact of so-called periopathogens, the results of recent systematic reviews and meta-analyses provided high quality evidence that quantitative characteristics of oral microbiome rather than just the presence of specific pathogen determine the disease pattern $(1,2,3,4)$. Qualitative microbiome essence seems to be relatively similar between healthy and diseased periodontal/peri-implant sites.

\section{Uvod}

Iako su parodontitis i periimplantitis uzročno povezani s takozvanim parodontopatogenim bakterijama, rezultati nedavno objavljenog sistematiziranog preglednog rada i metaanaliza dali su visokokvalitetne dokaze da obrazac bolesti određuju uglavnom kvantitativne karakteristike oralnoga mikrobioma, a ne samo određeni patogen $(1,2,3,4)$. Čini se da je mikrobiom kvalitativno razmjerno sličan u zdravom i bolesnom parodontu ili oko implantata, ali su uočene promje- 
However, some variable-based composition changes have been observed during inflammatory-associated periodontal tissue alteration around the tooth or dental implant $(1,2,3)$.

That is why it is important to consider the presence of periodontal pathogens even among healthy subjects and relevant theories of periodontitis and peri-implantitis development based on the phenomenon of periodontal pathogen imbalance and changes in host susceptibility levels $(5,6)$. The current shift of keystone pathogen theory to the periodontal pathogen disequilibrium theory was supported by the amount of evidence obtained over the last decade by using metagenomics and culturomics in research $(6,7,8)$.

There is a consensus in the scientific community about the fact that periodontally affected patients are characterized by the higher risk of peri-implantitis development. We must take into account that original bacteriological nature of periodontitis and peri-implantitis are similar, even though these lesions differ by their pattern of progression $(9,10,11)$. Such a difference could be related not only to the fact that periimplant tissue complex diverges from the periodontal one by its structure, but also to the possible dissimilarities in bacterial environment around the affected implant and the affected tooth $(10,11)$.

Moreover, further investigation of microbiome parameters at peri-implant and periodontal regions would be supportive for the continued differential analysis of their relationship with host genetic factors (11). In the systematic review of Nibali et al. (12), authors have mentioned that parameters of bacterial colonization patterns and their association with transcriptome information in the area of periodontal tissue alteration may be used for further correction of possible infectogenomics effects, which in turn could influence clinical development of the pathology. In other words, numerical verification of periodontal/peri-implant bacterial load patterns and their changes could be used as predictive criteria for diseases progression, or even for prediction of disease onset before any clinical signs of inflammation could be registered.

There are various methods used for quantification purpose of peri-implant and periodontal microbiomes and their differentiation, but question of routinely accessible and standardized approach that can estimate actual bacterial load at the different stages of each of these pathologies remains not fully resolved $(13,14)$.

That is why the objective of this study was to estimate the actual parameters of bacterial load in subgingival plaque during periodontitis and peri-implantitis pathologies using the RT-PCR (real-time polymerase chain reaction) method and evaluate their associations with clinical periodontal indicators.

\section{Material and Methods}

Five different groups of subjects were formed out of a cohort of dental patients from the "DM" (Uzhhorod, Ukraine) private dental clinic according to the formulated design. The patients included in the study groups were screened according to the following inclusion criteria: 1) presence of peri- ne u sastavu tijekom promjena parodontnog tkiva oko zuba ili zubnog implantata koje se događaju zbog upale $(1,2,3)$.

Zato se, uzimajući u obzir prisutnost parodontopatogenih bakterija čak i kod zdravih ispitanika, relevantne teorije razvoja parodontitisa i periimplantitisa temelje na narušenoj ravnoteži mikrobioma i promjeni osjetljivosti domaćina $(5$, 6). Teoriji nastanka zbog narušavanja ravnoteže parodontopatogenih bakterija ide u prilog količina dokaza dobivenih tijekom posljednjeg desetljeća metagenomičkim istraživanjima i istraživanjima na kulturama $(6,7,8)$.

Postoji konsenzus da su parodontološki pacijenti u većoj opasnosti od razvoja periimplantitisa, ako se uzme u obzir da je bakteriološki sastav parodontitisa i periimplantitisa sličan, iako se te lezije razlikuju po načinu progresije $(9,10,11)$. Takva razlika mogla bi biti povezana ne samo s činjenicom da se struktura periimplantantnog tkiva razlikuje od parodontnoga, nego su moguće i razlike u bakteriološkom sastavu oko zahvaćenog implantata i zahvaćenog zuba $(10,11)$.

Nadalje, još jedno istraživanje mikrobiomskih parametara u područjima oko implantata i parodonta išlo je u prilog daljnjoj diferencijaciji njihova odnosa s genetskim čimbenicima domaćina (11). U svojem sistematiziranom preglednom radu Nibali i suradnici (12) naveli su da se obrasci bakterijske kolonizacije i njihova povezanost $s$ transkriptnim informacijama u području promjene parodontnog tkiva mogu upotrijebiti za daljnju korekciju mogućih infektogenomskih učinaka, što bi zauzvrat moglo utjecati na klinički razvoj patološkog stanja. Drugim riječima, numerička provjera obrasca bakterijskog opterećenja parodontnih/periplantantnih tkiva i njihovih promjena mogu se upotrijebiti kao prediktivni kriteriji za napredovanje bolesti ili čak za predviđanje početka bolesti prije nego što se uoče bilo kakvi klinički znakovi upale.

Postoje različite metode koje se primjenjuju za kvantifikaciju periimplantantnog i parodontnog mikrobioma i njihove diferencijacije, ali još uvijek nema rutinski dostupnog i standardiziranog postupka kojim se može procijeniti stvarno bakterijsko opterećenje u različitim fazama svakoga od tih patoloških stanja $(13,14)$.

Zato je svrha ovog istraživanja bila procijeniti stvarne parametre bakterijskog opterećenja u subgingivnom plaku tijekom parodontitisa i periimplantitisa primjenom metode RT-PCR (lančane reakcije polimeraze u stvarnom vremenu) i njihovu povezanost $s$ kliničkim parodontološkim pokazateljima.

\section{Materijali i metode}

Ispitanici su bili pacijenti privatne stomatološke klinike $D M$ (Uzhhorod, Ukrajina) koji su podijeljeni u pet skupina. Oni uključeni u istraživanje pregledani su prema sljedećim kriterijima za uključivanje: 1) prisutnosti znakova parodontitisa/periimplantitisa; 2) sistemski su trebali biti zdravi; 
odontitis/peri-implantitis signs; 2) healthy systematic condition 3) willingness to participate in the research after explanation of all aspects of the study and the signature of patient's consent form. As exclusion criteria, used during the selection of patients into study groups, the following criteria were chosen: 1) presence of somatic comorbidities; 2) smoking; 3) systematic or sporadic medication intake that could potentially influence the oral microbiome during previous 14 days; 4) periodontitis or peri-implantitis management received during previous 6 months. According to above mentioned inclusion and exclusion criteria, 67 patients were distributed among the following three study groups: 28 patients were included in the group with mild/moderate periodontitis (MMP group), 16 patients - in the group with severe periodontitis (SP group), and 23 patients - in the group with peri-implantitis (PI group).

Control groups of subjects were formed out of dental patients according to the following inclusion criteria: 1) absence of periodontitis/peri-implantitis signs; 2) in cases of implant treatment implant screws were installed more than 12 months ago; 3) healthy somatic condition; 4) willingness to participate in the research after explanation of all aspects of the study and the obtained signature of patient's consent form. Exclusion criteria used for control groups were the same as for study groups. According to the above mentioned inclusion and exclusion criteria, 41 patients were distributed in the following two control groups: 21 patients were included in the healthy periodontal group, who have not undergone any implant procedure (HP group), and 20 patients in the healthy peri-implant group, who have received dental implant treatment more than 12 months ago with no clinical signs of peri-implantitis present at the time of clinical examination (HPI group).

\section{Periodontal examination}

Periodontal check-up was provided by previously calibrated three dental professionals with registration of such parameters as bleeding on probing (BOP), interdental clinical attachment loss (CAL) and periodontal probing depth (PPD) (15). At the time of initial clinical examination, each patient with clinical signs of periodontitis or peri-implantitis has undergone the procedure of peri-apical radiography.

Periodontitis staging was done according to the recommendation of 2017 World Workshop on the Classification of Periodontal and Peri-Implant Diseases and Conditions (16), considering which cases of I and II stages of periodontitis were clustered in the study group with mild/moderate periodontitis (MMP group), and cases with III stage periodontitis were clustered in the study group with severe periodontitis (SP group).

Identification of peri-implantitis cases was done according to the case definition criteria and diagnostic considerations described by Renvert et al. (17).

\section{Plaque sampling}

Subgingival plaque samples among patients of study groups were gathered from the sites with deepest periodontal probing parameters, which were identified with the use
3) spremnosti na sudjelovanje u istraživanju nakon sveobuhvatnog informiranja i potpisivanja pristanka.

Kriteriji za isključenje bili su: 1) prisutnost somatskih komorbiditeta; 2) pušenje; 3) sustavni ili povremeni unos lijekova koji su mogli utjecati na oralni mikrobiom unatrag 14 dana; 4) terapija parodontitisa ili periimplantitisa tijekom proteklih 6 mjeseci.

Zbog spomenutih kriterija uključivanja i isključivanja 67 pacijenata raspoređeno je u sljedeće tri ispitivane skupine: 28 pacijenata uvršteno je u skupinu s blagim/umjerenim parodontitisom (skupina MMP), 16 u skupinu s teškim parodontitisom (skupina SP) i 23 u skupinu s periimplantitisom (skupina PI).

Kontrolne skupine sastavljene su prema sljedećim kriterijima: 1) sudionici nemaju znakova parodontitisa/periimplantitisa; 2) u slučaju implantološke terapije implantati su im ugrađeni prije više od 12 mjeseci; 3) trebali su biti sistemski zdravi; 4) spremni su na sudjelovanje u istraživanju nakon informiranja i potpisivanja pristanka.

Kriteriji za isključenje bili su isti kao i za ispitivane skupine.

S obzirom na spomenute kriterije uključivanja i isključivanja, 41 pacijent raspodijeljen je u sljedeće dvije kontrolne skupine: 21 u skupinu sa zdravim parodontom bez implantata (skupina HP) i 20 pacijenata s implantatima pri čemu je implantat bio ugrađen prije barem 12 mjeseci, a u razdoblju kliničkog pregleda nije bilo kliničkih znakova periimplantitisa (skupima HPI).

\section{Parodontološki pregled}

Parodontološku kontrolu obavila su tri kalibrirana stručnjaka i pritom su bilježili sljedeće parametre: krvarenje nakon sondiranja (BOP), gubitak interdentalnog kliničkog pričvrstka (CAL) i dubinu sondiranja parodonta (PPD) (15). Tijekom početnoga kliničkog pregleda svakom pacijentu s kliničkim znakovima parodontitisa ili periimplantitisa učinjena je peripikalna rendgenska snimka.

Parodontitis je klasificiran prema preporukama Svjetske radionice o klasifikaciji parodontnih i periimplantantnih bolesti i stanja iz 2017. (16), pa su tako slučajevi s I. i II. stadijem parodontitisa uvršteni u ispitanu skupinu s blagim/ umjerenim parodontitisom (skupina MMP), a slučajevi s parodontitisom III. stadija u ispitivanu skupinu s teškim parodontitisom (skupina SP).

Slučajevi s periimplantitisom klasificirani su prema kriterijima o identifikaciji bolesti i dijagnostičkim razmatranjima koje su opisali Renvert i suradnici (17).

\section{Uzorkovanje plaka}

Uzorci subgingivnog plaka prikupljeni su od pacijenata u ispitivanim skupinama na mjestima s najdubljim vrijednostima sondiranja izmjerenima parodontološkom sondom North 
of North Carolina Periodontal Probe according to its $1 \mathrm{~mm}$ marking scale. Among patients of control groups, subgingival plaque samples were taken from the area of teeth and implants topographically analogical to those in patients with periodontal and peri-implant pathology. These sites were isolated before sampling procedure with cotton rolls, subsequently dried and mechanically cleaned with Gracey-curettes from the supragingival plaque. After that, paper-points were inserted in the pocket/sulcus area for 30 seconds. The paper points were placed in prepared sterile tubes after extraction and immediately transported within the next hour to the "Astra-Dia" laboratory (Uzhhorod, Ukraine).

\section{ParodontoScreen Procedure with RT-PCR}

The ParodontoScreen standardized test was provided in the laboratory conditions, which is aimed at identification of opportunistic pathogens in the gathered subgingival plaque samples with the use of real-time polymerase chain reaction (the RT-PCR method). Target microorganisms in the standardized ParodontoScreen analysis include the following: Aggregatibacter actinomycetemcomitans (A. actinomycetemcomitans), Porphyromonas gingivalis (P. gingivalis), Tannerella forsythia (T. forsythia), Prevotella intermedia (P. intermedia), Treponema denticola (T. denticola). The RT-PCR is based on the DNA-amplification process with further completion of polynucleotide chain with Taq-polymerase. The standardized ParodontoScreen test includes the following steps: allotment of DNA (preparation of specimen), PCR-amplification in real time condition with the use of specific reagents (mixture for PCR-amplification that is specific for all bacteria, mixture for PCR-amplification that is specific for opportunistic bacteria, mixture for PCR-amplification that is specific for human genomic DNA), registration of amplification results and their interpretation. The PCR and post-PCR processing was provided by the specific software. A laboratory analysis of all study and control samples was held by laboratory specialists with further representation of obtained results in the form of report (Figure 1).

Bacterial load levels of species were conventionally represented in "Lg (genome equivalents/sample)" units, also referred as $\mathrm{Lg}$ (GE/sample).

Detailed descriptions of the ParodontoScreen procedure aspects are presented on the manufacturer's website (18).

The research received acceptance from the Ethics Committee of Medical Faculty at Pavol Jozef Šafárik University (Košice, Slovak Republic).

\section{Statistical analysis}

A descriptive statistical analysis included an estimation of mean values and their standard deviations (SD) for each parameter (age, BOP, PPD, CAL, bacterial load of each microbial species) in all study and control groups. Statistical differences between groups in the means of all studied parameters were assessed using the independent Student-t test (19). Univariate analyses aimed at the evaluation of possible associations between detection frequency rate and mean bacterial load of each species during periodontal and periimplant diseases was provided as previously described in the
Carolina s ljestvicom od $1 \mathrm{~mm}$. Od pacijenata iz kontrolnih skupina uzorci subgingivnog plaka uzeti su na mjestima oko zuba ili implantata koja su topografski odgovarala mjestima kod pacijenata s parodontitisom i periimplantitisom. Prije postupka uzorkovanja ta su mjesta izolirana pamučnim svitcima, osušena i mehanički očišćcena kiretama Gracey od supragingivnog plaka. Zatim su papirnati štapići 30 sekunda umetnuti u džep/sulkus. Nakon vađenja pohranjeni su u pripremljene sterilne epruvete i odmah (najkasnije jedan sat) transportirani u laboratorij Astra-Dia (Uzhhorod, Ukrajina).

\section{ParodontoScreen s pomoću RT-PCR-a}

Standardizirani test ParodontoScreen proveden je u laboratorijskim uvjetima sa svrhom identifikacije oportunističkih patogena u prikupljenim uzorcima subgingivnog plaka metodom lančane reakcije polimeraze u stvarnom vremenu (RT-PCR). Ciljni mikroorganizmi u standardiziranoj analizi ParodontoScreen uključivali su sljedeće: Aggregatibacter actinomycetemcomitans (A. actinomycetemcomitans), Porphyromonas gingivalis (P. gingivalis), forsythia tannerella (T. forsythia), Prevotella intermedia (P. intermedia), Treponema T. denticola, (T. denticola). RT-PCR temelji se na postupku amplifikacije DNK s dovršavanjem polinukleotidnog lanca s Taq-polimerazom. Standardizirani test ParodontoScreen uključuje sljedeće: alokaciju DNK (priprema uzorka), PCR-amplifikaciju u stvarnom vremenu uz uporabu specifičnih reagensa (smjesa za PCR-amplifikaciju koja je specifična za sve bakterije, smjesa za PCR-amplifikaciju koja je specifična za oportunističke bakterije, mješavinu za PCR-amplifikaciju koja je specifična za humani genomski DNK) te registraciju rezultata amplifikacije i njihovu interpretaciju. PCR i post-PCR obrada obavljena je s pomoću specifičnog softvera. Laboratorijske analize svih ispitivanih i kontrolnih uzoraka obavili su laboratorijski stručnjaci s prikazom dobivenih rezultata u obliku izvještaja (slika 1.).

Razine bakterijskog opterećenja svake vrste uobičajeno su prikazane u jedinicama Lg (ekvivalenti genoma/uzorak), također su označene kao Lg (GE/uzorak).

Detaljan opis aspekata postupka ParodontoScreenom nalazi se na mrežnim stranicama proizvođača (18).

Istraživanje je prihvatilo Etičko povjerenstvo Medicinskog fakulteta Sveučilišta Pavol Jozef Safárik (Košice, Slovač$\mathrm{ka})$.

\section{Statistička analiza}

Deskriptivna statistička analiza uključivala je procjenu srednjih vrijednosti i njihovih standardnih devijacija (SD) za svaki parametar (dob, BOP, PPD, CAL, bakterijsko opterećnje za svaku vrstu mikroba) u svim ispitivanim i kontrolnim skupinama. Statističke razlike srednjih vrijednosti svih ispitivanih parametara između skupina ocjenjivane su neovisnim Studentovim t-testom (19). Univarijatne analize bile su usmjerene na procjenu moguće povezanosti između učestalosti otkrivanja i prosječnog bakterijskog opterećenja za svaku vrstu parodontnih i periimplantantnih bolesti, a provedene 


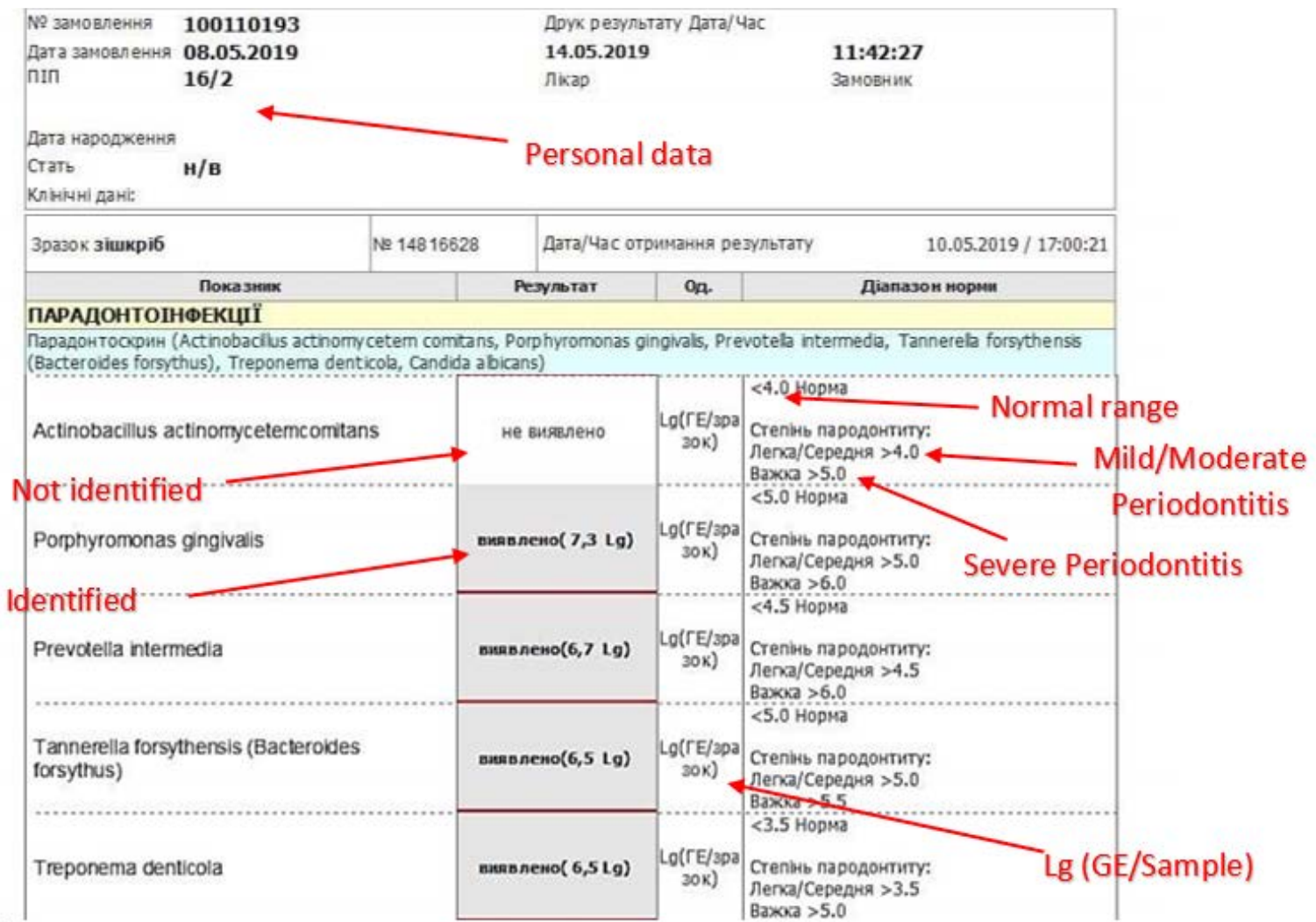

Figure 1 Report form of bacterial load of each periodontal pathogen established with "ParodontoScreen" test (original in Ukrainian) Slika 1. Izvješće o bakterijskom opterećenju za svaki parodontopatogeni mikroorganizam dobiveno testom ParodontoScreen (izvorno na ukrajinskom jeziku)

study of Ismail et al. (20), using p-values $<0,05$ as statistically significant for all parameters (21). The correlation between periodontal indicators and bacterial load parameters was assessed using the Spearman correlation coefficient as appropriate. A statistical analysis was provided using software package IBM SPSS Statistics (IBM Corporation) (19, 20), while data acquisition and organization was held in Microsoft Excel software (Microsoft Office 2019, Microsoft).

\section{Results}

Distribution of age, gender and initial clinical parameters registered among patients of study and control groups during primary examination are shown in Table 1.

Groups of severe periodontitis and peri-implantitis were characterized by the greatest levels of BOP, PPD and interdental CAL, which were statistically different from those noted among healthy periodontal and peri-implant sites and even at the sites with mild/moderate periodontitis $(\mathrm{p}<0$, 05). PPD and interdental CAL were statistically different during comparison of healthy periodontal and peri-implant sites $(\mathrm{p}<0,05)$, while there was no statistically significant difference between mean PPD and interdental CAL values in MMP and HPI groups $(p>0,05)$, except that clinical cases of those were distinguished by the presence and absence of clinically observed inflammation. MMP and HPI groups were significantly different considering the prevalence of $\mathrm{BOP}$ cases $(67,9 \%$ vs $35,0 \% ; \mathrm{p}<0,05)$. su kako je već opisano u istraživanju Ismaila i suradnika (20), pri čemu je p-vrijednost $<0,05$ postavljena kao statistički značajna za sve parametre (21). Povezanost između parodontoloških pokazatelja i parametara bakterijskog opterećenja određena je primjenom Spearmanova koeficijenta korelacije. Statistička analiza obavljena je softverskim paketom IBM SPSS Statistics (IBM Corporation) (19, 20), a za prikupljanje podataka i organizaciju korišsten je Microsoft Excel (Microsoft Office 2019., Microsoft).

\section{Rezultati}

Distribucija prema dobi, spolu i početnim kliničkim parametrima zabilježenima kod pacijenata ispitivanih $\mathrm{i}$ kontrolnih skupina tijekom primarnog pregleda, prikazana je u tablici 1.

Skupinu s teškim parodontitisom i periimplantitisom obilježavale su najviše razine BOP-a, PPD-a i interdentalnog CAL-a koji su se statistički razlikovali od onih zabilježenih za zdravi parodont i periimplantantno tkivo, pa čak i od mjesta $s$ blagim/umjerenim parodontitisom $(\mathrm{p}<0,05)$. PPD $\mathrm{i}$ interdentalni CAL statistički su se razlikovali usporedbom zdravoga parodonta i periimplantantnog tkiva $(\mathrm{p}<0,05)$, a nije bilo statistički značajne razlike između srednjih vrijednosti $\mathrm{PPD}$-a i interdentalnog CAL-a u skupinama MMP i HPI ( $p>0,05)$, osim što su se slučajevi razlikovali po prisutnosti i odsutnosti klinički evidentne upale. Skupine MMP i HPI značajno su se razlikovale s obzirom na učestalost slučajeva s BOP-om $(67,9$ $\%$ prema $35,0 \%$; $\mathrm{p}<0,05)$. 
Table 1 Distribution of baseline parameters among study and control groups

Tablica 1. Distribucija početnih parametara između ispitanih i kontrolnih skupina

\begin{tabular}{|c|c|c|c|c|c|}
\hline $\begin{array}{l}\text { Group/Parameters • } \\
\text { Skupina/parametri }\end{array}$ & $\begin{array}{l}\text { MMP group } \\
\quad(n=28)\end{array}$ & $\begin{array}{l}\text { SP group } \\
(n=16)\end{array}$ & $\begin{array}{l}\text { PI group } \\
(n=23)\end{array}$ & $\begin{array}{l}\text { HP group } \\
\quad(n=21)\end{array}$ & HPI group $(n=20)$ \\
\hline Age (years) • Dob (godine) & $44.3 \pm 1,2$ & $47.2 \pm 3,1$ & $51.5 \pm 2,4$ & $45.6 \pm 1,9$ & $52.8 \pm 1,8$ \\
\hline $\begin{array}{l}\text { Gender male } \% / \text { female } \% \bullet \\
\text { Spol muški } \% / \text { ženski } \%\end{array}$ & $57.1 \% / 42,9 \%$ & $43.8 \% / 56,2 \%$ & $52.2 \% / 47,3 \%$ & $47.6 \% / 52,4 \%$ & $50 \% / 50 \%$ \\
\hline BOP (\%) & $67.9 \%$ & $81.3 \%$ & $82.6 \%$ & $23.8 \%$ & $35.0 \%$ \\
\hline $\mathrm{PPD}(\mathrm{mm})$ & $4.2 \pm 0,4$ & $6.1 \pm 0,7$ & $5.2 \pm 0,6$ & $2.2 \pm 0,7$ & $3.7 \pm 0.5$ \\
\hline
\end{tabular}

MMP group - study group of patients with mild/moderate periodontitis, SP group - study group of patients with severe periodontitis, PI group - study group of patients with peri-implantitis, HP group - control group of patients with natural dentition and healthy periodontal status, HPI group - control group of patients with dental implants and healthy peri-implant status $\bullet$ Skupina MMP; group - skupina pacijenata s blagim/umjerenim parodontitisom, skupina SP - pacijenti s teškim parodontitisom, skupina PI - pacijenti s periimplantitisom, skupina HP - kontrolna skupina pacijenata s prirodnom denticijom i zdravim parodontom, skupina HPI - kontrolna skupina pacijenata s dentalnim implantatima i zdravim periimplantatnim tkivom

The highest detection frequency rate using the real-time PCR method was observed for $P$. gingivalis in all healthy and diseased periodontal cases, while the lowest detection rate was noted for A. actinomycetemcomitans in all analyzed samples. The highest frequency of detection among all healthy peri-implant cases was noted for T. forsythia, which statistically differs from healthy periodontal cases $(\mathrm{p}<0,05)$. Also, higher detection rates were noted for $T$. denticola $(\mathrm{p}>0,05)$, P. intermedia $(\mathrm{p}<0,05)$ and A. actinomycetemcomitans $(\mathrm{p}<$ $0,05)$ in healthy peri-implant samples compared to healthy periodontal samples. Such a tendency could be interpreted as indirect evidence of microbiome structure redistribution in the areas of installed implants compared to the area of natural teeth.

In all analyzed cases detection frequency of each microorganism increased with the pathology progression. Provided univariate analyses dedicated to the identification of significant dependencies between bacteria detection frequency and periodontal/peri-implant disease revealed that such associations were noted for: severe periodontitis and P. gingivalis ( $\mathrm{p}$ $<0,05)$, T. denticola $(\mathrm{p}<0,05)$, T. forsythia $(\mathrm{p}<0,05)$; mild/ moderate periodontitis and T. denticola $(\mathrm{p}<0,05)$, T. forsythia $(\mathrm{p}<0,05)$; peri-implantitis and T. denticola $(\mathrm{p}<0,05), T$. forsythia $(\mathrm{p}<0,05)$, A. actinomycetemcomitans $(\mathrm{p}<0,05)$ (Table 2).
Najveća frekvencija detekcije primjenom PCR metode u stvarnom vremenu zabilježena je za $P$. gingivalis u svim slučajevima sa zdravim i bolesnim parodontnim tkivom, a najmanja je za $A$. actinomycetemcomitans u svim analiziranim uzorcima. Najveća frekvencija detekcije kod svih slučajeva sa zdravim periimplantatom zabilježena je za vrstu T. forsythia koja se statistički značajno razlikovala od zdravoga parodonta $(\mathrm{p}<0,05)$. Također su zabilježene veće stope detekcije za vrste $T$. denticola $(\mathrm{p}>0,05)$, P. intermedia $(\mathrm{p}<0,05)$ i A. actinomycetemcomitans $(\mathrm{p}<0,05)$ u zdravim uzorcima periiplantantnog tkiva u usporedbi sa zdravim parodontom. Takva tendencija može se protumačiti kao indirektni dokaz preraspodjele strukture mikrobioma u područjima ugrađenih implantata u odnosu prema području prirodnih zuba.

U svim analiziranim slučajevima frekvencija detekcije svakog mikroorganizma povećavala se s napredovanjem patologije. Univarijatnom analizom kojom se utvrdivala ovisnost između frekvencije detekcije bakterija i parodontne/periimplantantne bolesti, otkriveno je da takva povezanost postoji u slučaju teškog periodontitisa i bakterija $P$. gingivalis ( $\mathrm{p}$ $<0,05)$, T. denticola $(\mathrm{p}<0,05)$, T. forsythia $(\mathrm{p}<0,05)$; blagog/umjerenog parodontitisa i vrsta T. denticola $(\mathrm{p}<0,05)$, T. forsythia $(\mathrm{p}<0,05)$; periimplantitisa i vrsta T. denticola ( $\mathrm{p}$ $<0,05)$, T. forsythia $(\mathrm{p}<0,05)$, A. actinomycetemcomitans ( $\mathrm{p}$ $<0,05)$ (tablica 2.).

Table 2 Detection frequency rates and results of univariate analyses for the interrelation with periodontal and peri-implant diseases Tablica 2. Frekvencija otkrivanja i rezultati univarijatne analize za odnos s parodontnim i periimplantantnim bolestima

\begin{tabular}{|c|c|c|c|c|c|c|c|c|}
\hline $\begin{array}{c}\text { Groups/Periodontal pathogen } \\
\text { Skupina/parodontopatogene } \\
\text { bakterije }\end{array}$ & $\begin{array}{l}\text { MMP } \\
\text { group } \\
(\mathrm{n}=28)\end{array}$ & $\begin{array}{c}\text { p-value } \\
\text { p-vrijednost }\end{array}$ & $\begin{array}{c}\text { SP group } \\
(n=16)\end{array}$ & $\underset{\text { p-vrijednost }}{\text { p-value }} \bullet^{\circ}$ & $\begin{array}{c}\text { PI group } \\
(\mathbf{n}=23)\end{array}$ & $\begin{array}{c}\text { p-value } \bullet \\
\text { p-vrijednost }\end{array}$ & $\begin{array}{l}\text { HP group } \\
\quad(n=21)\end{array}$ & $\begin{array}{l}\text { HPI group } \\
\quad(n=20)\end{array}$ \\
\hline P. gingivalis (\%) & 92.9 & $p>0.05$ & 100 & $\mathrm{p}<0.05$ & 78.3 & $\mathrm{p}>0.05$ & 85.7 & 70.0 \\
\hline T. denticola $(\%)$ & 78.6 & $\mathrm{p}<0.05$ & 93.8 & $\mathrm{p}<0.05$ & 82.6 & $\mathrm{p}<0.05$ & 61.9 & 65 \\
\hline T. forsythia (\%) & 75.0 & $\mathrm{p}<0.05$ & 8.5 & $\mathrm{p}<0.05$ & 82.6 & $\mathrm{p}<0.05$ & 52.3 & 75 \\
\hline P. intermedia (\%) & 82.1 & $\mathrm{p}>0.05$ & 87.5 & $\mathrm{p}>0.05$ & 73.9 & $\mathrm{p}>0.05$ & 52.3 & 65 \\
\hline A. actinomycetemcomitans (\%) & 14,3 & $p>0.05$ & 18,8 & $p>0.05$ & 39,1 & $\mathrm{p}>0.05$ & 4.8 & 10.0 \\
\hline
\end{tabular}

MMP group - study group of patients with mild/moderate periodontitis, SP group - study group of patients with severe periodontitis, PI group - study group of patients with peri-implantitis, HP group - control group of patients with natural dentition and healthy periodontal status, HPI group - control group of patients with dental implants and healthy peri-implant status $\bullet$ Skupina MMP; group - skupina pacijenata s blagim/umjerenim parodontitisom, skupina SP - pacijenti s teškim parodontitisom, skupina PI - pacijenti s periimplantitisom, skupina HP - kontrolna skupina pacijenata s prirodnom denticijom i zdravim parodontom, skupina HPI - kontrolna skupina pacijenata s dentalnim implantatima i zdravim periimplantatnim tkivom 
Even though detection frequency of some microorganisms increased during pathology compared to healthy state, such associations between detection frequency values and periodontal/peri-implant diseases were not statistically proven because of an uneven distribution of such frequency rates between the study subjects in each group (inter-subject detection frequency variations).

Bacterial load parameters demonstrated a significant increase tendency within periodontitis progression, and during the comparison of healthy and diseased periodontal/periimplant sites. According to the provided univariate analyses, each registered mean bacterial load level was statistically associated with periodontitis or peri-implantitis pathology, upon condition that bacterial load levels of healthy periodontal and peri-implant sites were used as reference for equiparation (Table 3).
Iako se frekvencija detekcije nekih mikroorganizama povećala progresijom bolesti u usporedbi sa zdravim stanjem, takva povezanost između vrijednosti frekvencije detekcije i parodontnih/periimplantatnih bolesti nisu statistički dokazane zbog neravnomjerne distribucije frekvencija između ispitanika u svakoj skupini (varijacije frekvencije detekcije između subjekata).

Parametri bakterijskog opterećenja pokazali su značajno povećanje tendencije pri progresiji parodontitisa i usporedbi zdravoga i bolesnog parodonta/područja oko implantata. Prema rezultatima univarijatne analize svaka registrirana srednja razina bakterijskog opterećenja statistički je bila povezana s parodontitisom ili periimplantitisom kada su razine bakterijskog opterećenja u zdravom i bolesnom parodontu i periimplantatnom tkivu korištene kao referentne vrijednost (tablica 3.).

Table 3 Mean levels of bacterial load and results of univariate analyses for the association with periodontal and peri-implant diseases Tablica 3. Srednje razine bakterijskog opterećenja i rezultati univarijatne analize za povezanost s parodontnim i periimplantatnim bolestima

\begin{tabular}{|c|c|c|c|c|c|c|c|c|}
\hline $\begin{array}{c}\text { Groups/Periodontal pathogen } \\
\text { Skupina/parodontopatogene } \\
\text { bakterije }\end{array}$ & $\begin{array}{l}\text { MMP } \\
\text { group } \\
(\mathrm{n}=28)\end{array}$ & $\begin{array}{c}\text { p-value } \\
\text { p-vrijednost }\end{array}$ & $\underset{(n=16)}{\text { SP group }}$ & $\begin{array}{c}\text { p-value } \\
\text { p-vrijednost }\end{array}$ & $\begin{array}{c}\text { PI group } \\
(n=23)\end{array}$ & $\begin{array}{c}\text { p-value } \\
\text { p-vrijednost }\end{array}$ & $\begin{array}{l}\text { HP group } \\
(\mathbf{n}=21)\end{array}$ & $\begin{array}{l}\text { HPI group } \\
\quad(n=20)\end{array}$ \\
\hline P. gingivalis (Lg GE/sample • uzorak) & $5.5 \pm 0.7$ & $\mathrm{p}<0.05$ & $6.9 \pm 0,5$ & $\mathrm{p}<0.05$ & $6.0 \pm 0,4$ & & $2.4 \pm 0,2$ & $3.9 \pm 0.4$ \\
\hline T. forsythia (Lg GE/sample • uzorak) & $5.0 \pm 0.4$ & $\mathrm{p}<0.05$ & $5.6 \pm 0.4$ & $\mathrm{p}<0,05$ & $5.2 \pm 0.4$ & $\mathrm{p}<0.05$ & $1.9 \pm 0,2$ & $3.5 \pm 0.5$ \\
\hline P. intermedia (Lg GE/sample • uzorak) & $4.9 \pm 0.5$ & $\mathrm{p}<0.05$ & $6.3 \pm 0,5$ & $\mathrm{p}<0.05$ & $5.3 \pm 0.6$ & $\mathrm{p}<0.05$ & $2.7 \pm 0.3$ & $2.9 \pm 0.1$ \\
\hline T. denticola (Lg GE/sample • uzorak) & $4.1 \pm 0.6$ & $\mathrm{p}<0.05$ & $6.4 \pm 0,3$ & $\mathrm{p}<0.05$ & $4.7 \pm 0.5$ & $\mathrm{p}<0.05$ & $2.9 \pm 0.2$ & $3.2 \pm 0.2$ \\
\hline $\begin{array}{l}\text { A. actinomycetemcomitans } \\
\text { (Lg GE/sample } \bullet \text { uzorak) }\end{array}$ & $4.7 \pm 0.5$ & $\mathrm{p}<0.05$ & $5.0 \pm 0,7$ & $\mathrm{p}<0.05$ & $4.9 \pm 0.6$ & $\mathrm{p}<0.05$ & $1.1 \pm 0.4$ & $1.9 \pm 0.6$ \\
\hline
\end{tabular}

MMP group - study group of patients with mild/moderate periodontitis, SP group - study group of patients with severe periodontitis, PI group - study group of patients with peri-implantitis, HP group - control group of patients with natural dentition and healthy periodontal status, HPI group - control group of patients with dental implants and healthy peri-implant status • Skupina MMP; group - skupina pacijenata s blagim/umjerenim parodontitisom, skupina SP - pacijenti s teškim parodontitisom, skupina PI - pacijenti s periimplantitisom, skupina HP - kontrolna skupina pacijenata s prirodnom denticijom i zdravim parodontom, skupina HPI - kontrolna skupina pacijenata s dentalnim implantatima i zdravim periimplantatnim tkivom

Statistical analysis of overall obtained data helped to register specific values of correlation between such parameters as BOP, PPD, CAL and bacterial load of each target periodontal pathogen. It was noted that BOP parameter was not statistically associated with any of identified microorganisms ( $\mathrm{p}$ $>0,05$ ), while PPD was related to the increased load levels of each studied bacteria apart from $P$. intermedia, even though such correlation values were categorized as weak. CAL has shown analogical pattern of interrelation with increased bacterial load of each studied periopathogen apart from $P$. intermedia despite the fact that such correlation values were lower
Statistička analiza dobivenih podataka pomogla je otkriti specifične vrijednosti korelacije između parametara kao što su BOP, PPD, CAL i bakterijskog opterećenja za svaki ciljani parodontopatogeni mikroorganizam. Primijećeno je da parametar BOP nije bio statistički značajno povezan ni s jednim identificiranim mikroorganizmom ( $p>0,05)$, a PPD je bio povezan $s$ povećanom razinom opterećenja za svaku proučavanu bakteriju, osim P. intermedia, iako su takve korelacijske vrijednosti kategorizirane kao slabe. CAL je slijedio sličan obrazac uzajamne povezanosti s povećanim bakterijskim opterećenjem svakom ispitivanom parodontopatogenom bakte-

Table 4 Correlations between bacterial load of periopathogens and clinical parameters of BOP, PPD and CAL

Tablica 4. Korelacije između bakterijskog opterećenja parodontopatogenim mikroorganizmima i kliničkih parametara BOP-a, PPD-a i CAL-a

\begin{tabular}{|c|c|c|c|c|c|c|}
\hline \multirow{2}{*}{$\begin{array}{c}\text { Study parameters/Periodontal pathogen } \\
\text { Klinički parametri/parodontopatogene } \\
\text { bakterije }\end{array}$} & \multicolumn{2}{|c|}{ BOP } & \multicolumn{2}{|c|}{ PPD } & \multicolumn{2}{|c|}{ CAL } \\
\hline & $\mathbf{r}$ & $\underset{\text { p-vrijednost }}{\text { p-value }}$ & $\mathbf{r}$ & $\underset{\text { p-vrijednost }}{\text { p-value }}$ & $\mathbf{R}$ & $\underset{\text { p-vrijednost }}{\text { p-value }}$ \\
\hline P. gingivalis & 0.12 & $p>0.05$ & 0.28 & $\mathrm{p}<0.05$ & 0.24 & $\mathrm{p}<0.05$ \\
\hline T. forsythia & 0.09 & $\mathrm{p}>0.05$ & 0.20 & $\mathrm{p}<0.05$ & 0.18 & $\mathrm{p}<0.05$ \\
\hline P. intermedia & 0.11 & $p>0.05$ & 0.13 & $\mathrm{p}>0.05$ & 0.11 & $\mathrm{p}>0.05$ \\
\hline T. denticola & 0.14 & $p>0.05$ & 0.21 & $\mathrm{p}<0.05$ & 0.21 & $\mathrm{p}<0.05$ \\
\hline A. actinomycetemcomitans & 0.18 & $p>0.05$ & 0.37 & $\mathrm{p}<0.05$ & 0.28 & $\mathrm{p}<0.05$ \\
\hline
\end{tabular}

$\mathrm{BOP}-$ bleeding on probing $=$ krvarenje nakon sondiranja, $\mathrm{PPD}-$ periodontal probing depth $=$ dubina sondiranja parodonta, $\mathrm{CAL}-\mathrm{clinical}$ attachment loss = gubitak kliničkog pričvrstka 
compared to those registered with PD. The highest correlation values were found between PPD and bacterial load parameters of $A$. actinomycetemcomitans $(\mathrm{r}=0,37 ; \mathrm{p}<0,05)$ and P. gingivalis $(\mathrm{r}=0,28 ; \mathrm{p}<0,05)$; and also between $\mathrm{CAL}$ and bacterial load values of $A$. actinomycetemcomitans ( $\mathrm{r}=0,28 ; \mathrm{p}$ $<0,05)$ and $P$. gingivalis $(\mathrm{r}=0,24 ; \mathrm{p}<0,05)$ (Table 4).

\section{Discussion}

The newest model of periodontitis and peri-implantitis development considering the presence of keystone pathogen is not capable for provoking disease itself, but is responsible for formation of specific bacterial interrelation under which the overall level of pathogenicity increases at the problematic periodontal or peri-implant areas $(7,8)$. Most of the previous studies have been devoted to the analysis of microbial ecosystem during peri-implantitits and periodontitis, which can be categorized in two groups: studies aimed at verification of specific pathogens and studies aimed at detailed identification of complex microbiota. Such approaches of detailed quantitative and qualitative analyses of peri-implantitis and periodontitis biofilms structure support possibilities for treatment individualization, thus gaining effectiveness of epigenetic therapeutic modalities (22). Also such concepts of examination help minimize the risk of superinfection development, as previously described during the use of broad-spectrum antibiotics for peri-implantitis treatment (23).

In our research we have provided the estimates of actual bacterial load levels of five periodontopathogen species in subgingival plaque during periodontitis and peri-implantitis pathologies using the RT-PCR method. The main advantages of using the PCR-method in dentistry and periodontology are reasoned by time and cost-efficiency, higher sensitivity compared to other approaches, possibility to reproduce results in the same manner, and relatively easy algorithm for quantification of obtained parameters $(24,25)$. Recently, real-time polymerase chain reaction has been applied for qualitative analysis, thus completely replacing the method of bacterial culture (14).

The results of our study are concordant with previously obtained findings that could be summarized in the way that an increase in load levels of periodontopathogens associated with the development of periodontitis and peri-implantitis $(26,27)$. Despite that, it should be noted that interrelation changes between different species in subgingival microbiome, and specific individual host response mechanisms could play a more pronounced role in periodontal or peri-implant pathology development than just quantity variations of bacterial load, but such an aspect will be addressed in our further studies since it is beyond the scope of this research $(1,2,3$, 22, 26).

A previously statistically important increase in bacterial frequency was noted while comparing healthy periodontal and peri-implant conditions and states of periodontitis and peri-implantitis. However, no significant difference of bacterial frequency was registered between gingivitis and muco- rijom, osim za $P$. intermedia, unatoč činjenici da su takve korelacijske vrijednosti niže u usporedbi s onima zabilježenima za PD. Najveće korelacijske vrijednosti utvrđene su za parametar PPD i bakterijsko opterećenje vrstama $A$. actinomycetemcomitans $(\mathrm{r}=0,37 ; \mathrm{p}<0,05)$ i $P$. gingivalis $(\mathrm{r}=0,28 ; \mathrm{p}$ $<0,05)$, a također između vrijednosti CAL-a i vrijednosti bakterijskog opterećenja vrstama $A$. acinomycetemcomitans $(\mathrm{r}=$ $0,28 ; \mathrm{p}<0,05)$ i $P$. gingivalis $(\mathrm{r}=0,24 ; \mathrm{p}<0,05)$ (tablica 4.).

\section{Rasprava}

Prema najnovijem modelu nastanka parodontitisa i periimplantitisa smatra se da ključni patogeni sami ne izazivaju bolest, ali su odgovorni za stvaranje specifične bakterijske flore u kojoj se ukupna razina patogena povećava u problematičnim područjima $(7,8)$. Većina dosadašnjih istraživanja o analizi mikrobiološkog ekosustava u slučaju parodontitisa i perimplantitisa može se svrstati u dvije skupine - onu usmjerenu na verifikaciju specifičnih patogena i onu usmjerenu na detaljnu identifikaciju složenih mikrobioma. Takvi pristupi detaljne kvantitativne i kvalitativne analize biofilma parodontitisa i periimplantitisa omogućuju individualizaciju liječenja, čime se postiže učinkovitost epigenetskih terapijskih modaliteta (22). Takvi koncepti također pomažu minimizirati rizik od razvoja superinfekcije, kao što je već opisano tijekom primjene antibiotika širokog spektra za liječenje periimplantitisa (23).

U našem istraživanju dali smo procjenu stvarne razine bakterijskog opterećenja za pet vrsta parodontopatogenih mikroorganizama u subgingivnom plaku tijekom parodontitisa i periimplantitisa metodom RT-PCR. Glavne prednosti primjene te metode $\mathrm{u}$ dentalnoj medicini i parodontologiji uključuju brzinu i cijenu testa, veću osjetljivost u usporedbi s drugim postupcima, mogućnost reprodukcije rezultata i razmjerno jednostavan algoritam za kvantifikaciju dobivenih parametara $(24,25)$. Nedavno je lančana reakcija polimeraze u stvarnom vremenu primijenjena za kvalitativnu analizu kao zamjenska metoda za bakterijske kulture (14).

Rezultati našeg istraživanja podudaraju se s ranijim nalazima koji bi se mogli sažeti tako da se s razvojem parodontitisa i periimplantitisa povećava opterećenje parodontopatogenim bakterijama $(26,27)$. Unatoč tomu treba istaknuti da bi interakcije između različitih vrsta u subgingivnom mikrobiomu i specifični pojedinačni mehanizmi odgovora domaćina mogli imati izraženiju ulogu u razvoju parodontne ili periimplantantne bolesti od samih kvantitativnih varijacija bakterijskog opterećenja, ali taj će se aspekt analizirati u daljnjim istraživanjima i nadmašuje okvire ovog rada $(1,2,3,22,26)$.

Uspoređujući uvjete zdravog parodonta i periimplantatnog tkiva i stanja parodontitisa i periimplantitisa, prije je utvrđeno statistički značajno povećanje frekvencije detekcije bakterija, a nije zabilježena značajna razlika u frekvenciji detekcije bakterija između gingivitisa i mukozitisa u usporedbi s parodontitisom i periimplantitisom (28). Isti je obrazac uočen i u našem istraživanju, iako smo primijenili kriterije bakterijskog opterećenja umjesto opisane frekvencije detekcije bakterija - parodontitis III. stupnja karakterizira veće bakterijsko opterećenje u usporedbi s parodontitisom I. stupnja 
sitis compared to periodontitis and peri-implantitis respectively (28). The same pattern was noted in our study, even though we have used criteria of bacterial load instead of previously described bacterial frequency: III stage periodontitis was characterized by higher bacterial load compared to the I stage periodontitis or healthy periodontal status, while the same tendency was also noted during comparison of healthy peri-implant region and peri-implantitis lesion.

In the study of Torrungruanag et al. (29), the prevalence of $P$. ginigualis and $T$. denticola among patients with severe periodontitis was relatively similar to the detection rate frequency registered in our research, while detection rate frequency of T. forsythia and P. intermedia in our study was comparatively lower, which can be explained by the smaller number of study subjects in the corresponding group. It is important to notice that in both studies the prevalence/ detection frequency of $A$. actinomycetemcomitans was the lowest both among periodontitis and healthy sites, while bacterial load of this species was also the lowest one.

A significant difference was found in values of bacterial load between healthy periodontal sites and those with signs of periodontitis, while the same tendency was also noted during evaluation of peri-implant healthy sites and those with peri-implantitis. Moreover, the absolute difference of levels of microorganisms' bacterial load was also found during equiparation of healthy periodontal sites and healthy peri-implant regions, while statistically significant variations were noted considering bacterial load of $P$. gingivalis, T. forsythia and $A$. actinomycetemcomitans $(\mathrm{p}<0,05)$. Nevertheless, the results of our research should be interpreted with caution, since in another study of microbiota composition it was found that even though variations of species have been observed between affected and unaffected peri-implant/periodontal sites, such differences were smaller compared to inter subject differences (30). Analogical facts have been described in a number of previous studies, wherein individual oral microbiome composition and its associated changes were the most predominant factors of pathology development, and on which further treatment algorithms should be targeted (22, 25, and 26).

Due to the complex aim of this study and possibility to analyze both laboratory parameters of actual bacterial load parameters and clinical signs among periodontitis and periimplantitis sites, we have found correlation values between specific load levels of $A$. actinomycetemcomitans, $P$. gingivalis, T. forsythia, P. intermedia, T. denticola and average parameters of BOP, PPD and CAL. Based on the obtained results it can be summarized that PPD and CAL parameters demonstrated a weak but statistically significant correlation with bacterial load of all studied bacterial species except $P$. intermedia, while BOP has shown no correlation with any of analyzed periodontopathogen loads. In the study of Octavia et al. (31), it was shown that scaling and root planing among patients with periodontitis, associated not only with the reduction of pocket depth and gingival bleeding index but also with decrease of these parameters, was also statistically correlated with the reduction of $P$. gingivalis and $P$. forsythia amounts counted in the subgingival plaque. On the other hand, in the larg- ili zdravim parodontom, a slična je tendencija uočena i tijekom usporedbe zdravoga periimplantantnog tkiva i lezije periimplantitisa.

U istraživanju Torrungruanaga i suradnika (29) prevalencija vrsta $P$. ginigvalis i $T$. denticola među pacijentima s teškim parodontitisom bila je razmjerno slična nalazima u našem istraživanju, a učestalost vrsta $T$. forsythia i $P$. intermedia u našem istraživanju bila je razmjerno manja, što se može objasniti manjim brojem ispitanika u odgovarajućoj skupini. Važno je istaknuti da je u oba istraživanja prevalencija vrste A. actinomycetemcomitans bila najmanja i u slučaju parodontitisa i u zdravim uvjetima, dok je bakterijsko opterećenje ove vrste bilo najmanje.

Utvrđena je značajna razlika u vrijednostima bakterijskog opterećenja između zdravog parodonta i mjesta sa znakovima parodontitisa, pri čemu je ista tendencija uočena i tijekom usporedbe zdravoga periimplantantnog tkiva i sluznice zahvaćene periimplantitisom. Stoviše, apsolutna razlika u razinama bakterijskog opterećenja također je utvrđena tijekom usporedbe zdravoga parodonta i zdravoga periimplantantnog područja, a zabilježene su statistički značajne varijacije kad se uzme u obzir bakterijsko opterećenje vrstama $P$. gingivalis, T. forsythia i A. actinomycetemcomitans ( $\mathrm{p}<0,05)$. Ali takve rezultate našeg istraživanja treba tumačiti s oprezom jer je u drugom istraživanju o sastavu mikrobioma utvrđeno da su, iako su primijećene varijacije vrsta između zahvaćenih i zdravih mjesta, takve razlike bile manje nego među subjektima (30). Analogne su činjenice opisane u mnogobrojnim dosadašnjim istraživanjima u kojima su individualni sastav oralnog mikrobioma i pridružene promjene bili dominantni čimbenici razvoja patologije i na koje trebaju biti usmjereni daljnji algoritmi liječenja $(22,25,26)$.

Zbog složenoga cilja ovog istraživanja i mogućnosti analize laboratorijskih i stvarnih parametara bakterijskog opterećenja i kliničkih znakova na područjima parodontitisa i periimplantitisa, pronašli smo korelacijske vrijednosti između specifičnih razina opterećenja vrstama $A$. actinomycetemcomitans, P. gingivalis, T. forsythia, P. intermedia, T. denticola i prosječnih parametara BOP-a, PPD-a i CAL-a. Na temelju dobivenih rezultata može se reći da su parametri PPD-a i CAL-a pokazali slabu, ali statistički značajnu povezanost $s$ bakterijskim opterećenjem svim ispitivanim bakterijskim vrstama, osim vrstom $P$. intermedia, a BOP nije pokazao povezanost $s$ analiziranim opterećenjem parodontopatogenim mikroorganizmima. U istraživanju Octavija i suradnika (31) pokazalo se da je struganje i poliranje korijena pacijentima s parodontitisom povezano ne samo sa smanjenjem dubine džepa $\mathrm{i}$ indeksom krvarenja gingive, nego je smanjenje tih parametara bilo i statistički povezano sa smanjenjem broja bakterija $P$. gingivalis i $P$. forsythia u subgingivnom plaku. $S$ druge strane, u najvećem epidemiološkom istraživanju iz parodontologije primjenom PCR metode u stvarnom vremenu (29), utvrđeno je da je $P$. gingivalis čak i u maloj količini značajno povezana s teškim parodontitisom $s$ najvećim razinama PPDa i CAL-a, a bakterijsko opterećenje vrstama $A$. actinomycetemcomitans, $T$. denticola i $P$. intermedia trebalo bi dosegnuti neke granične razine da bi se statistički povezale $s$ napredovalom bolešću parodonta (29). Takva tendencija primijećena je 
est periodontal epidemiological study with the use of the real time PCR method (29), it was found that the presence of $P$. gingivalis even in small amounts is strongly associated with severe periodontitis with greatest levels of PPD and CAL, while the bacterial load of $A$. actinomycetemcomitans, T. denticola and P. intermedia should reach some marginal levels to be statistically related to the advanced periodontal pathology (29). Such a tendency was also observed in our research: all patients with severe periodontitis and greatest values of PPD and CAL revealed $100 \%$ detection frequency of $P$. gingivalis, bacterial load which was also the greatest compared to that of other species.

Resuming the obtained outcomes, it could be highlighted that the use of PCR method helps identify main periodontal pathogens that play predominant role in periodontitis and peri-implantitis development. Moreover, identification of such pathogens during periodontitis pathology and before implant placement could be used for optimization of oral cavity ecosystem balance to provide more advantageous conditions for further implant functioning, thus reducing risks of possible peri-implant complications during a longterm monitoring. One of the further perspectives for using PCR method in implantological practice was described in the Carinci F. et al. study (32), in which the authors, based on the criteria of total bacterial load, pointed to the possibility of using implants with polymeric chlorhexidine inside-chamber layering. In this way, a reduction of bacterial load was obtained, which also could be interpreted as a prevention measure against peri-implantitis development.

Limitations of this research are linked to a relatively small number of participants in study and control groups. Also, the design of the study was characterized by restricted conditions for controlling laboratory phase of research, since all in vitro analyses were performed by lab specialists with further provision of obtained results in the form of reports. Taking into consideration the abovementioned, it was not possible to estimate the level of possible laboratory service bias, even though all used equipment was granted and checked for conformance marking, and laboratory specialists were previously calibrated for periodontally-aimed types of studies.

Despite the limitations mentioned, it was found that the progression of periodontal disease and the presence of periimplantitis pathology are related to the absolute increase of bacterial load parameters of species such as A. actinomycetemcomitans, P. gingivalis, T. forsythia, P. intermedia, T. denticola with different levels of statistical dependencies. While using the RT-PCR method for the quantification of microbiome structure, it should be noted that the parameter of bacterial detection frequency is characterized by less sensitive interrelation with periodontal and peri-implant diseases, compared to the parameter of absolute bacterial load.

\section{Conclusions}

Periodontitis and peri-implantitis are associated with the same microbial pathogens, even though the distribution pattern of their bacterial load and detection frequency parameters registered with the RT-PCR could be distinct and linked i u našem istraživanju - svim pacijentima s teškim parodontitisom i najvećim vrijednostima PPD-a i CAL-a otkrivena je 100-postotna frekvencija $P$. gingivalis čije je bakterijsko opterećenje bilo najveće u usporedbi s drugim vrstama.

Nadovezujući se na dobivene rezultate, moglo bi se istaknuti da primjena PCR-a pomaže u prepoznavanju glavnih parodontopatogenih mikroorganizama koji imaju glavnu ulogu u razvoju parodontitisa i periimplantitisa. Štoviše, identifikacija tih patogena tijekom parodontitisa i prije ugradnje implantata može se koristiti za optimizaciju ravnoteže ekosustava usne šupljine kako bi se osigurali povoljniji uvjeti za funkcioniranje implantata i smanjio rizik od mogućih komplikacija tijekom dugoročnog praćenja. Jednu od daljnjih mogućnosti upotrebe PCR metode u implantološkoj praksi opisali su F. Carinci i suradnici u svojem istraživanju (32) u kojemu su autori na temelju kriterija ukupnoga bakterijskog opterećenja argumentirali mogućnost upotrebe implantata $s$ polimernim klorheksidinskim slojem unutar komore. $\mathrm{Na}$ taj način postignuto je smanjenje bakterijskog opterećenja, što se također može tumačiti kao preventivna mjera protiv razvoja periimplantitisa.

Ograničenja ovog istraživanja povezana su s razmjerno malim brojem ispitanika u ispitivanim i kontrolnim skupinama. Mogućnosti kontrole laboratorijske faze istraživanja također su bile ograničene jer su sve analize in vitro obavili laboratorijski stručnjaci, a rezultate su prezentirali u obliku izvještaja. Uzimajući u obzir navedeno, nije se mogla procijeniti razina eventualne pristranosti u laboratorijskim testovima, iako je sva korištena oprema bila provjerena i odobrena, a laboratorijski stručnjaci prije toga su bili kalibrirani za parodontološke analize.

Unatoč opisanim ograničenjima, ustanovljeno je da su progresija parodontitisa bolesti i prisutnost periimplantitisa bile povezane $s$ apsolutnim povećanjem parametara bakterijskog opterećenja vrstama kao što su $A$. actinomycetemcomitans, $P$. gingivalis, T. forsythia, P. intermedia, T. denticola s različitim razinama statističkih ovisnosti. Tijekom korištenja metode RT-PCR za kvantifikaciju strukture mikrobioma, treba napomenuti da je parametar frekvencije detekcije bakterija karakteriziran manjom povezanošću s parodontnim i periimplantantnim bolestima u usporedbi s parametrom apsolutnoga bakterijskog opterećenja.

\section{Zaključak}

Parodontitis i periimplantitis povezani su s istim mikrobnim patogenima, iako se obrazac distribucije njihova bakterijskog opterećenja i parametara frekvencije detekcije registriranih s pomoću RT-PCR-a mogao razlikovati i dovesti 
to the individual patient-related conditions and the severity stage of pathology. Generally, the development of periodontal and peri-implant lesions is related to real raise of bacterial counts estimated for $A$. actinomycetemcomitans, P. gingivalis, T. forsythia, P. intermedia, T. denticola. None of the studied periopathogens presented a statistically compelling relationship with clinical bleeding on probing parameter, while the greatest correlation between periodontal pocket depth and the loss of clinical attachment level were registered for $P$. gingivalis, T. forsythia, T. denticola and A. actinomycetemcomitans bacterial loads. Quantitative verification of periodontal bacterial load levels before implantation could serve to advance arguments for the need to improve oral health and balance the microbial ecology, thus reducing the risk of potential peri-implant complications during a time-lapse survey.

\section{Conflict of interest}

The authors report no conflict of interest and the article is not funded or supported by any research grant. u korelaciju s pojedinačnim stanjima povezanima s pacijentom i stupnjem uznapredovalosti patologije. Općenito, razvoj parodontnih i periimplantatnih lezija povezan je s povećanjem broja bakterija $A$. actinomycetemcomitans, P. gingivalis, T. forsythia, P. intermedia, T. denticola. $\mathrm{Ni}$ jedna od proučenih parodontopatogenih bakterija nije pokazala statistički značajnu vezu s kliničkim parametrom krvarenja nakon sondiranja, a najveća povezanost između dubine parodontnog džepa i gubitka razine kliničkoga pričvrstka zabilježena je za bakterijsko opterećenje vrstama $P$. gingivalis, T. forsythia, T. denticola $i$ A. actinomycetemcomitans. Kvantitativna provjera razine bakterijskoga opterećenja parodontopatogenim vrstama prije implantacije mogla bi poslužiti kao preliminarni argument za potrebu prilagodbe ravnoteže oralnoga ekosustava sa svrhom smanjenja rizika od razvoja potencijalnih komplikacija oko implantata.

\section{Sukob interesa}

Autori navode da nisu bili u sukoba interesa te da istraživanje nije financirano novcem iz znanstvenih projekata.

\section{Sažetak}

Svrha rada: Željelo se procijeniti stvarne parametre bakterijskog opterećenja u subgingivnom plaku metodom RT-PCR (lančanom reakcijom polimeraze u stvarnom vremenu) u slučaju parodontitisa i periimplantitisa te njihovu povezanost s kliničkim parodontološkim pokazateljima. Materijali i metode: Prema postavljenom studijskom dizajnu složeno je pet skupina ispitanika - s blagim/umjerenim parodontitisom, $\mathrm{s}$ teškim parodontitisom, $\mathrm{s}$ periimplantitisom, zdravim parodontom i zdravim periimplantatnim tkivom. Uzorci subgingivnog plaka uzeti su papirnatim štapićima koji su 30 sekunda bili umetnuti u džep/sulkus. Proveden je standardni test ParodontoScreen za identifikaciju ciljnih oportunističkih patogena (A. actinomycetemcomitans, P. gingivalis, T. forsythia, P. intermedia, T. denticola) RT-PCR metodom. Rezultati: Parametri bakterijskog opterećenja pokazali su značajnu tendenciju porasta pri progresiji parodontitisa i periimplantitisa. Univarijantnom analizom svaka ciljna srednja razina bakterijskog opterećenja statistički je bila povezana s parodontitisom ili periimplantitisom ( $p$ $<0,05$ ) kada su parametri bakterijskog opterećenja na zdravim mjestima korišteni kao referentni podatci. Najveće korelacijske vrijednosti ustanovljene su između parametara dubine sondiranja i bakterijskog opterećenja bakterijama A. actinomycetemcomitans $(r=0,37 ; p<0,05)$ i $P$. gingivalis $(r=$ $0,28 ; p<0,05)$ te također između gubitka kliničkog pričvrstka i bakterijskog opterećenja bakterijama A. actinomycetemcomitans $(r=0,38 ; p<0,05)$ i $P$. gingivalis $(r=0,24 ; p<0,05)$. Zaključak: Parodontitis i periimplantitis povezani su $\mathrm{s}$ istim mikrobnim patogenima, iako su se obrasci distribucije bakterijskog opterećenja i parametri zabilježeni s pomoću RT-PCR-a mogli razlikovati i povezati s individualnim stanjima povezanima s pacijentima i uznapredovalošću patologije.
Zaprimljen: 15. studenoga 2019. Prihvaćen: 24. siječnja 2020.

Adresa za dopisivanje Goncharuk-Khomyn Myroslav Nacionalno sveučilišt Uzhhorod Stomatološki fakultet Uzhhorod, Ukrajina myroslav.goncharuk-khomyn@ uzhnu.edu.ua

\section{Ključne riječi}

parodontitis; periimplantitis; bakterijsko opterećenje; lančana reakcija polimeraze u realnom vremenu

\section{References}

1. Patini R, Staderini E, Lajolo C, Lopetuso L, Mohammed H, Rimondini L, et al. Relationship between oral microbiota and periodontal disease: A systematic review. Eur Rev Med Pharmacol Sci. 2018 Sep;22(18):5775-5788.

2. Guerra F, Mazur M, Ndokaj A, Corridore D, La GT, Polimeni A, et al. Periodontitis and the microbiome: a systematic review and metaanalysis. Minerva Stomatol. 2018 Dec;67(6):250-258.

3. Rakic M, Grusovin MG, Canullo L. The Microbiologic Profile Associated with Peri-Implantitis in Humans: A Systematic Review. Int J Oral Maxillofac Implants. 2016 Mar-Apr;31(2):359-68.

4. Lafaurie GI, Sabogal MA, Castillo DM, Rincón MV, Gómez LA, Lesmes YA, el al. Microbiome and microbial biofilm profiles of peri-implantitis: a systematic review. J Periodontol. 2017 Oct;88(10):1066-1089.

5. Savić I, Bošnjak A, Beader N, Lovrić Ž, Salihagić A, Gašparac I. Anaerobic Bacteria in Implants and Homologous Teeth 2-14 Years after Implantation. Acta Stomatol Croat. 2018 Sep;52(3):193202.

6. Hujoel P, Zina LG, Cunha-Cruz J, Lopez R. Historical perspectives on theories of periodontal disease etiology. Periodontol 2000. 2012 Feb;58(1):153-60.

7. Hajishengallis G, Darveau RP, Curtis MA. The keystone-pathogen hypothesis. Nat Rev Microbiol. 2012 Oct;10(10):717-25.
8. Lasserre JF, Brecx MC, Toma S. Oral microbes, biofilms and their role in periodontal and peri-implant diseases. Nat Rev Microbiol. 2012 Oct;10(10):717-25.

9. Carinci F, Gaudio RM. Peri-implantitis and periodontitis: Use of bacteriological test in dental practice. Forensic Medicine and Anatomy Research. 2013;1(03):50-56.

10. Legović R, Aurer A. Evaluation of Periodontal and Periimplant Tissues in Patients with Dental Implants. Acta Stomatol Croat. 2012;46(2):97-104

11. Plančak D, Musić L, Puhar I. Quorum sensing of periodontal pathogens. Acta Stomatol Croat. 2015 Sep;49(3):234-41.

12. Nibali L, Di lorio A, Onabolu O, Lin GH. Periodontal infectogenomics: systematic review of associations between host genetic variants and subgingival microbial detection. J Clin Periodontol. 2016 Nov;43(11):889-900.

13. D’Ercole S, Catamo G, Piccolomini R. Diagnosis in periodontology: a further aid through microbiological tests. Crit Rev Microbiol. 2008;34(1):33-41.

14. Kotsilkov K, Popova C, Boyanova L, Setchanova L, Mitov I. Comparison of culture method and real-time PCR for detection of putative periodontopathogenic bacteria in deep periodontal pockets. Biotechnology \& Biotechnological Equipment. 2015;29(5):996-1002. 
15. Eickholz P. Clinical periodontal diagnosis: probing pocket depth, vertical attachment level and bleeding on probing. Perio. 2004;1(1):75-80.

16. Tonetti MS, Greenwell H, Kornman KS. Staging and grading of periodontitis: Framework and proposal of a new classification and case definition. J Clin Periodontol. 2018 Jun;45 Suppl 20:S149-S161.

17. Renvert S, Persson GR, Pirih FQ, Camargo PM. Peri-implant health, peri-implant mucositis, and peri-implantitis: Case definitions and diagnostic considerations. J Clin Periodontol. 2018 Jun;45 Suppl 20:S278-S285

18. Wang R, Lagakos SW, Ware JH, Hunter DJ, Drazen IM. Statistics in medicine - reporting of subgroup analyses in clinical trials. N Engl J Med. 2007 Nov 22;357(21):2189-94.

19. Ismail FB, Ismail G, Dumitriu AS, Baston C, Berbecar V, Jurubita $R$, et al. Identification of subgingival periodontal pathogens and association with the severity of periodontitis in patients with chronic kidney diseases: a cross-sectional study. Biomed Res Int. 2015;2015:370314.

20. Ho R. Handbook of univariate and multivariate data analysis and interpretation with SPSS. Chapman and Hall/CRC; 2006.

21. Martellacci L, Quaranta G, Patini R, Isola G, Gallenzi P, Masucci L. A Literature Review of Metagenomics and Culturomics of the Peri-implant Microbiome: Current Evidence and Future Perspectives. Materials. 2019;12(18):3010.

22. Verdugo F, Laksmana T, Uribarri A. Systemic antibiotics and the risk of superinfection in peri-implantitis. Arch Oral Biol. 2016 Apr;64:39-50.

23. Maheaswari R, Kshirsagar JT, Lavanya N. Polymerase chain reaction: A molecular diagnostic tool in periodontology. J Indian Soc Periodontol. 2016 Mar-Apr;20(2):128-35.
24. Marin MJ, Figuero E, Herrera D, Sanz M. Quantitative Analysis of Periodontal Pathogens Using Real-Time Polymerase Chain Reaction (PCR). J Indian Soc Periodontol. 2016 Mar-Apr;20(2):128-35.

25. Kim EH, Joo JY, Lee YJ, Koh JK, Choi JH, Shin Y, et al. Grading system for periodontitis by analyzing levels of periodontal pathogens in saliva. PLoS One. 2018 Nov 26;13(11):e0200900.

26. Naginyte M, Do T, Meade J, Devine DA, Marsh PD. Enrichment of periodontal pathogens from the biofilms of healthy adults. Sci Rep. 2019 Apr 2;9(1):5491.

27. Cortelli SC, Cortelli JR, Romeiro RL, Costa FO, Aquino DR, Orzechowski PR, et al. Frequency of periodontal pathogens in equivalent peri-implant and periodontal clinical statuses. Arch Oral Biol. 2013 Jan;58(1):67-74.

28. Torrungruang K, Jitpakdeebordin S, Charatkulangkun O, Gleebbua Y. Porphyromonas gingivalis, Aggregatibacter actinomycetemcomitans, and Treponema denticola/Prevotella intermedia co-infection are associated with severe periodontitis in a Thai population. PLoS One. 2015 Aug 27;10(8):e0136646.

29. Yu XL, Chan Y, Zhuang L, Lai HC, Lang NP, Keung LW, et al. Intra-oral single-site comparisons of periodontal and peri-implant microbiota in health and disease. Clin Oral Implants Res. 2019 Aug;30(8):760-776.

30. Octavia M, Soeroso Y, Kemal Y, Sunarto H, Bachtiar BM. Microbial effects (Porphyromonas gingivalis, Tannerella forsythia) after scaling and root planing. In Journal of Physics: Conference Series. 2018;1073(6):062011.

31. Carinci F, Lauritano D, Bignozzi CA, Pazzi D, Candotto V, Santos de Oliveira P, et al. A New Strategy Against Peri-Implantitis: Antibacterial Internal Coating. Int J Mol Sci. 2019 Aug 9;20(16). 